REVISTA CIENCIAS BIOMÉDICAS

RESEÑA BIBLIOGRÁFICA

\title{
LA CIUDAD EN TIEMPOS DE EPIDEMIAS
}

\section{MÚNERA-CAVADÍA ALFONSO, ROMÁN-ROMERO RAÚL}

Fue en el siglo XIX, cuando en Cartagena surgieron las preocupaciones centrales por la historia de las enfermedades contagiosas, lo que dio lugar a discusiones de importancia sobre el tema de la salud y las epidemias. En primer lugar, se radicalizaron las posturas ideológicas entre los abanderados del pensamiento liberal, por una parte, y los defensores de las tradiciones, por la otra; y, en segundo lugar, se presentaron constantes ataques epidémicos como el de la viruela, la fiebre amarilla y el cólera, entre otras que suscitaron confrontaciones entre discursos y prácticas médicas, lo que llevó

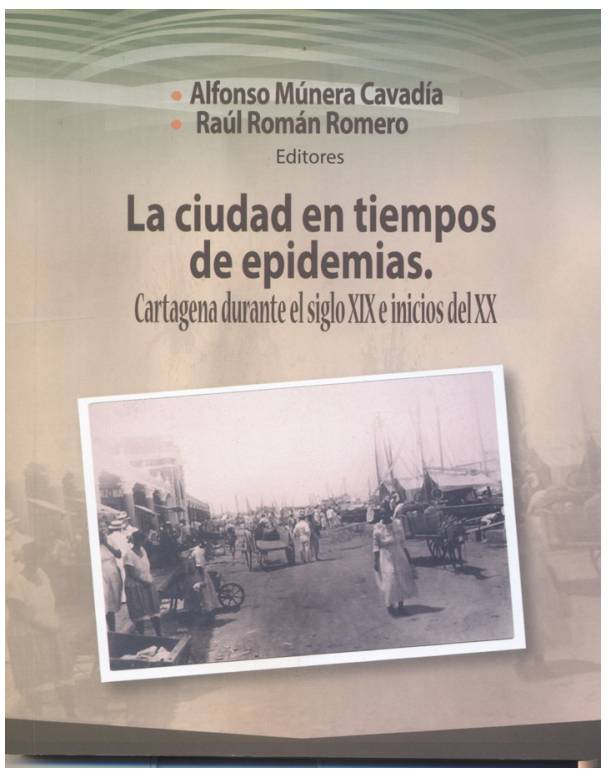
necesariamente a elaborar escritos con códigos sanitarios, recomendaciones higiénicas y justificaciones para prevenir el contagio.

En casi todos los países latinoaméricanos estos escritos representaron discursos médicos enfrentados, y se convirtieron en documentos de gran utilidad para conocer cómo en momentos determinados se había hecho frente a los vectores de contagio. De esta forma en el siglo XIX no solo se describió y difundió la evolución de los tratamientos médicos y se reconoció la labor de médicos en el desarrollo de la medicina, sino que, además, se presentó un progreso importante en los tratamientos de las enfermedades y, lo más importante, quedó abundante documentación tanto en Europa como en América Latina, que se convirtió en fuente principal para el desarrollo de agendas investigativas posteriores.

Este libro, tiene como editores a los profesores Alfonso Múnera Cavadía y a Raúl Román Romero. Son autores de los cuatro capítulos que integran el texto: Andrea Miranda Pestana, Berena Pacheco Gambin, Wacely Matute Tapia, Orlando de Avila Pertuz, Lorena Guerrero Palencia, Vicky de León Mendoza, Maico Pitalúa Fruto, Luisinho Salas Martínez y Elkin Javier Monroy. Texto que visibiliza una importante época de la historia médica cartagenera, que además viene a ser un espejo donde se observa el devenir de una ciudad presa del abandono y la destrucción, que habiendo dejado de ser la joya hispánica del ultramar y víctima de diversas pestes busca elevarse sobre su ruinas. 